\title{
Práticas grupais como dispositivo na promoção da saúde
}

\author{
| ${ }^{1}$ João Leite Ferreira Neto, ${ }^{2}$ Luciana Kind I
}

Resumo: O artigo apresenta e discute dados produzidos por uma pesquisa sobre práticas de grupo desenvolvidas por Equipes de Saúde da Família (ESF) dos nove Distritos Sanitários de Belo Horizonte. Foram realizadas entrevistas com gerentes de Unidades Básicas de Saúde e profissionais das ESF, grupos focais com usuários e observaçōes participantes em grupos em andamento nas unidades. $\mathrm{Na}$ análise dos dados, buscamos privilegiar a dimensão processual e de construção histórica das práticas investigadas, através da discussão de cinco aspectos: (1) motivos para a realização dos grupos; (2) mudanças de enfoque das práticas grupais; (3) dimensōes informativa e participativa dos grupos; (4) efeitos e (5) avaliação das práticas grupais. As análises apontam que as práticas de grupo apresentam múltiplas facetas quanto à organização dos serviços e da assistência, à função e aos objetivos propostos por diferentes equipes e à sua configuração. Observa-se uma mudança de enfoque, ainda incipiente, de práticas centradas na doença para a composição de grupos por novos eixos estruturantes, em conformidade com o que se preconiza nas diretrizes do município para a atenção básica. Os dados revelam impactos das práticas grupais na diminuição de consultas individuais e na otimização do vínculo entre usuários, profissionais e serviços. Os resultados apontam a tensão entre o dispositivo "consulta individual" e o dispositivo "práticas de grupo". O primeiro se apresenta como marcado pelo foco na doença, enquanto o dispositivo "práticas de grupo" desfocaliza a doença, trazendo à tona outras dimensōes de vida, associadas à promoção da saúde.

> Palavras-chave: Promoção da saúde; práticas de grupo; saúde da família; dispositivo.

\footnotetext{
1 Professor do Programa de Pós-Graduação em Psicologia da PUC Minas; Doutor em Psicologia Clínica (PUC-SP). Endereço eletrônico: jleite. bhe@terra.com.br

2 Professora do Programa de Pós-Graduação em Psicologia da PUC Minas; Doutora em Saúde Coletiva (IMS-UERJ). Endereço eletrônico: lukind@ gmail.com
}

Recebido em: 12/11/2009 Aprovado em: 03/05/2010 
Este artigo apresenta e discute parte dos dados produzidos pela pesquisa "Práticas de grupo como estratégia de promoção da saúde", realizada nos anos 2007 e 2009. Seu objetivo foi conhecer e avaliar as práticas de grupo, como instrumento de promoção da saúde, desenvolvidas por Equipes de Saúde da Família (ESF) nos nove distritos sanitários de Belo Horizonte.

A Saúde da Família é entendida atualmente como sendo uma "estratégia de reorientação do modelo assistencial" do Sistema Único de Saúde - SUS (BRASIL, 2004). Desde o final da década de 1990, abandonou seu estatuto inicial de ser um programa localizado, implantado em 1994, para se tornar uma estratégia estruturante dos sistemas municipais de saúde visando à reorientação da atenção básica (ESCOREL et al., 2007; GIOVANELLA, 2008). Sua ação transforma o cenário das práticas de saúde desenvolvidas na atenção básica, na medida em que estabelece laços de compromisso e corresponsabilização entre cada ESF e um conjunto específico de cerca de 3.000 a 4.500 pessoas ou de 1.000 famílias de uma determinada área. Portanto, busca transformar o modelo liberal privado de assistência que, tradicionalmente, organiza o fluxo assistencial através do recebimento da demanda espontânea. Cada equipe assume responsabilidade pelo cuidado integral à saúde da população a ela vinculada, através de açôes de promoção da saúde, prevenção, recuperação, reabilitação de doenças e agravos mais frequentes, bem como de intervir nos fatores de risco vividos por essa comunidade. $\mathrm{O}$ impacto das ações dessas equipes sobre o aumento da cobertura assistencial e a redução dos índices de mortalidade infantil é notável. Entretanto, estudos abordam seus impasses na tentativa de transformar em prática cotidiana o ideário do SUS (GRISOTTI; PATRÍCIO, 2006).

Entendemos promoção da saúde como proposta emergente de um debate estabelecido na década de 1970, decorrente da publicação do Relatório Lalonde (1981/1974), documento de trabalho do Ministério da Saúde do Canadá, cujo objetivo central era o enfrentamento dos custos crescentes de assistência médica, não acompanhados pela resolutividade na atenção médico-centrada, particularmente no caso das doenças crônicas (BUSS, 2003). O documento é, portanto, marcado pela busca de uma racionalidade econômica e de uma proposta de utilizar a promoção da saúde dentro de uma estratégia global para a organização dos serviços de saúde. Um debate internacional acompanhou essa iniciativa e tem como marcos a I Conferência Internacional sobre Cuidados Primários em Saúde, 
realizada em 1978 em Alma-Ata, e a I Conferência Internacional sobre Promoção da Saúde, em Otawa, 1986 (BRASIL, 2001).

Concentramo-nos na apresentação dos dados produzidos na pesquisa, sem retomar os vários aspectos do debate, suas polêmicas e seus problemas. Boa parte da literatura sobre o tema aborda seus avanços e impasses (CZERESNIA, 2003; CARVALHO, 2004; CASTIEL, 2004; CARVALHO; GASTALDO, 2008). Em outro trabalho de cunho mais teórico-conceitual, contendo uma revisão bibliográfica da temática, expusemos nossa perspectiva de tomar a promoção como objeto de problematização, evitando aderir a uma avaliação dualista, seja entendendo-a como essencialmente progressista, seja como essencialmente conservadora. Buscamos evidenciar essa tensão polarizadora que a atravessa, analisando a promoção da saúde como um campo problemático, composto de discursos e práticas, saberes e poderes, atravessado, concomitantemente, por dimensões regulatórias e disciplinares, e dimensōes participativas e emancipatórias (FERREIRA NETO; KIND, 2010).

Oriunda de um contexto primeiro-mundista de organização estatal dos serviços de saúde, a promoção da saúde tem uma clara função de controle das populaçôes, dentro do que Foucault denominava de biopoder (FOUCAULT, 1988). Por outro lado, o debate e as práticas da promoção trazem claros avanços em relação às propostas de prevenção, focalizadas nas doenças e na ação médica sobre o corpo doente e sobre os grupos de risco, ao propor uma noção de saúde positiva e multidimensional, com ações participativas que têm por foco a população em seu ambiente (BUSS, 2003).

Em nosso eixo específico de investigação, lembramos que a utilização de grupos como estratégia de intervenção em saúde é antiga e que seus primórdios remontam às iniciativas de Joseph Pratt, em um hospital geral de Boston, com pacientes tuberculosos (BECHELLI; SANTOS, 2004). Seu formato era assumidamente educativo, batizado de "aulas", consistindo em uma breve palestra sobre higiene e tratamento da doença, seguida de uma sessão de perguntas e discussões (FERNÁNDEZ, 2006). Esse modo de intervenção atravessou a história das práticas de saúde ocidentais, tanto no âmbito público quanto nos grupos não-governamentais de ajuda mútua. No Brasil, grupos organizados em torno de doentes crônicos, como hipertensos e diabéticos, são comuns nas UBSs, e o procedimento de palestra seguida de perguntas é bastante prevalente. 
1122 Contudo, nossa pesquisa aponta mudanças desse modo de atenção, devidas a um conjunto de razões e abordadas na apresentação dos dados produzidos.

Demarcar essa distinção é importante, uma vez que a literatura aponta como uma das diferenças entre prevenção de doenças e promoção da saúde o fato de que, enquanto aquela tem como alvo os grupos de risco e patologias específicas, esta tem em vista o conjunto da população e um conjunto ampliado de temas em saúde (BUSS, 2003). Dentro de nosso percurso, os grupos de promoção foram nossa busca inicial, mesmo que em nossa produção de dados investigamos o conjunto das práticas de grupo conduzidas pela equipe da unidade indicada.

Em 2006, a Secretaria Municipal de Saúde de Belo Horizonte (SMSA) desenvolveu uma ampla discussão de um documento sobre Atenção Básica em todas as UBSs, que foi posteriormente publicado (TURCI, 2008). Nele, preconiza-se que as ações de promoção da saúde nas unidades devem se pautar em três abordagens. Na primeira, individual, atuando sobre os modos de vida saudáveis em todas as intervenções, seja no acolhimento, seja nas consultas. $\mathrm{Na}$ segunda, coletiva, organizando grupos "sob novos eixos estruturantes" (TURCI, 2008 , p. 188) e não mais pela doença ou pelos agravos. Nesse caso, o liame passa a ser a perspectiva de mudança nos hábitos de vida. Na terceira, comunitária, buscam-se parcerias intersetoriais com iniciativas comunitárias ou da própria rede. Apesar de nossa pesquisa focar fundamentalmente a segunda e a terceira abordagens - as ações coletivas -, reconhecemos não haver uma identidade absoluta entre promoção e práticas grupais. A promoção pode e deve comparecer em todas as ações assistenciais, inclusive na atenção individual.

\section{Metodologia}

Trabalhamos com a hipótese de que as práticas de grupo como estratégia de promoção da saúde não representavam uma tendência hegemônica nas ações das ESF, uma vez que a tradição mais presente na saúde é a de grupos organizados em torno de doenças e agravos. Isso foi parcialmente confirmado quando fizemos o primeiro contato com a Gerência de Assistência da Secretaria Municipal de Saúde para iniciarmos o trabalho de campo. Nesse contato inicial, que tinha por finalidade otimizar a organização da entrada em campo, as representantes da Gerência de Assistência que nos receberam avaliaram que as práticas de grupo na rede municipal de saúde são ainda muito "tradicionais" e marcadas pelo saber biomédico. 
Esse contato cumpriu o objetivo de dar ciência às instâncias cabíveis na $\mathrm{PBH}$ com as quais a pesquisa se relacionaria, direcionando-nos às gerências dos nove Distritos Sanitários do município. Os gerentes distritais indicaram UBSs, em suas respectivas regionais, cujas ESFs desenvolviam práticas grupais como estratégia de promoção da saúde, mais consolidadas e que já caminhavam na direção de atuações pensadas a partir dos novos eixos estruturantes. Nesse contato, apenas duas das nove gerências indicaram mais de uma unidade onde se realizavam práticas de grupo num enfoque de promoção da saúde. Nas demais, de um total de 144 unidades, ficamos restritos a uma opção apenas, confirmando, assim, a avaliação preliminar da Secretaria, de que as práticas grupais ainda possuem um caráter majoritariamente biomédico.

Seguindo as indicações das gerências distritais, chegamos às nove UBSs, onde utilizamos os seguintes procedimentos: entrevista com os gerentes de unidade; entrevista com os profissionais da ESF indicada pelo gerente, grupos focais com usuários dos variados grupos que ocorriam na unidade; observaçôes participantes em grupos conduzidos pelas equipes. Todos esses procedimentos tiveram como lócus a unidade de saúde da equipe pesquisada. Tínhamos um primeiro contato com a gerência da unidade e, após a indicação da equipe escolhida, agendávamos a entrevista com esta. Posteriormente, o grupo focal era organizado com a ajuda da equipe e convites para o encontro eram entregues pelos agentes comunitários para membros das diversas práticas de grupos que ocorriam na unidade. Em uma das unidades, não foi realizado o grupo focal por causa de dificuldades encontradas para o agendamento. Dos oito grupos focais realizados, em dois houve apenas dois participantes. Mesmo com quorum baixo, os dados produzidos foram considerados relevantes para o estudo. Nos demais grupos focais, contouse com uma média de dez participantes por grupo.

O roteiro de entrevistas de gerentes e profissionais abordava uma descrição geral do trabalho na unidade e outros temas comuns às entrevistas direcionadas aos membros das equipes, tais como: quais eram as práticas desenvolvidas; quais as formas de encaminhamento dos usuários; quais os tipos de registro e avaliação dos resultados; como ocorria a adesão, qual a relação com as consultas individuais; quais as dinâmicas dos encontros; que vantagens e desvantagens dos grupos podiam ser percebidas. Aos profissionais também era perguntado sobre suas referências teórico-metodológicas e modos de condução dos grupos. Já os 
grupos focais tinham um roteiro menos dirigido, iniciados com uma proposta de que cada um relatasse sua experiência no grupo do qual participava.

As observações participantes foram realizadas em 11 grupos que acontecem regularmente nas UBS. A escolha dos grupos foi feita a partir de indicaçōes dos profissionais de saúde entrevistados. Ocorreu uma exceção a essa conduta de coleta de dados na UBS 1. Nessa unidade, o grupo de adolescentes fora encerrado, mas havia registro das sessões em vídeo feito durante a coleta de dados da socióloga que atuou ali como parceira. O registro das observações foi do tipo lápis e papel, anotando-se de forma cursiva e livre os principais eventos e falas que aconteciam nos grupos. $\mathrm{O}$ foco da observação era o tipo de condução do grupo, número de participantes e profissionais, grau de participação dos usuários, formatação da proposta do encontro e local de realização do encontro. As falas mais expressivas manifestas ao longo de alguns encontros foram registradas literalmente. Em dois grupos, com maior volume de participantes e condução menos estruturada, temse um registro aproximado de usuários presentes. O número total de usuários que participavam dos grupos observados é de aproximadamente 184, ao lado de 38 trabalhadores da saúde envolvidos de alguma forma em sua condução.

Como forma de sistematização de contatos e de produzir reflexôes preliminares sobre os dados coletados, os pesquisadores trabalharam com um diário de campo contendo observações sobre o conjunto da trajetória de pesquisa. A triangulação de técnicas qualitativas diversificadas possibilitou a expressão de diferentes formas e ângulos de se conhecer as práticas grupais desenvolvidas por ESFs. O trabalho de campo foi desenvolvido entre maio de 2007 e agosto de 2008, e 306 sujeitos foram envolvidos na pesquisa, como observado no quadro 1. Transcrições das entrevistas e grupos focais e notas das observaçóes participantes compuseram o corpus da pesquisa.

Quadro 1: Sujeitos envolvidos na pesquisa

\begin{tabular}{|c|c|}
\hline Técnica de coleta & \# de sujeitos \\
\hline Entrevistas & 21 profissionais \\
\hline Grupos focais & 63 usuários \\
\hline Observação participante & $\begin{array}{l} \pm 184 \text { usuários } \\
38 \text { trabalhadores de saúde }\end{array}$ \\
\hline TOTAL & \pm 306 \\
\hline
\end{tabular}


A direção metodológica buscou uma produção de dados plural, que permitisse uma análise das práticas grupais a partir dos múltiplos processos que as constituíam, evitando uma simplificação unidimensional e seguindo indicaçôes metodológicas preconizadas por Foucault (2003).

$\mathrm{Na}$ análise dos dados, trabalhamos com procedimentos analíticos clássicos das pesquisas qualitativas, como, por exemplo, atentar para a repetição dos elementos comuns presentes no material. Associado a isso, buscamos discernir os elementos relevantes presentes, a partir do olhar e da escuta em perspectiva dos pesquisadores, mesmo quando sua aparição fosse reduzida ou mesmo única. Repetição e relevância foram dois princípios metodológicos utilizados (TURATO, 2003).

Orientados pelos princípios da repetição e da relevância dos temas encontrados, privilegiamos a dimensão processual das práticas investigadas. Por isso, intitulamos nossos eixos de análise de "movimentos". Ainda que nossa investigação não se distinga radicalmente de procedimentos mais clássicos de análises temáticas de material, nosso objetivo foi evitar uma apresentação e discussão dos dados que congelassem experiências e relatos, que nossa vivência em campo os percebeu como portadores de dinamismo e variaçóes ao longo do tempo. Intentamos dirimir o efeito de cristalização que, por vezes, acompanha o processo de categorização dos dados. Muitos elementos que serão expostos e discutidos nos diferentes movimentos reconhecidos nos dados se interpenetram, sem se restringirem a categorias temáticas específicas.

\section{Resultados e discussão}

Antes de expormos os movimentos analíticos possibilitados pela análise dos dados, cabe uma descrição das práticas de grupo encontradas, conferindo certos contornos que serão retomados posteriormente. Foram encontrados diferentes formatos de grupos nas unidades envolvidas no estudo, o que nos permite fazer uma primeira distinção. As diferentes práticas realizadas podem ser divididas entre grupos de conversa e grupos de atividades, mesmo reconhecendo que alguns grupos conjuguem, num mesmo encontro, ambas as dimensões. Os grupos de conversa comportam um espectro que vai desde as práticas tradicionais centradas em prevenção (hipertensos, diabéticos, gestantes), até as práticas com foco na promoção da saúde, a partir dos novos eixos estruturantes, com diferentes denominações (grupos de convivência, de promoção da saúde, de qualidade de 
vida). Junto com eles, são desenvolvidos, com incentivo crescente por parte da SMSA, grupos de atividades (lian gong, caminhadas, tarde dançante, artesanato). A adesão a esses grupos de atividades é crescente e sua importância cada vez mais reconhecida. Uma das profissionais entrevistadas, vinculada à UBS 4, chegou a afirmar que os grupos de atividades são os genuínos grupos de promoção da saúde, porque nos grupos de conversa fala-se sobre ela, enquanto que nos outros ela é praticada. Mesmo sem concordar integralmente com essa afirmativa, é inegável o impacto dos grupos de atividades na vida dos usuários.

No modo de condução dos grupos, encontramos um leque de variações. Muitos grupos se apresentam centrados e dependentes do saber especializado. Os grupos que buscam outros focos têm uma condução menos dependente dos médicos e enfermeiros, sendo muitos deles conduzidos pelos agentes comunitários de saúde (ACS):

O grupo de atividade física, ele é mediado pelos agentes comunitários de saúde com algumas intervenções de fisioterapia de algumas universidades que vem, orienta, ensina as posições corretas, mas é o ACS o grande mediador. (Profissional, UBS 2).

Houve, inclusive, uma prática observada, na qual uma usuária ficou responsável por propor a dinâmica de aquecimento:

Foi o momento de acontecer uma brincadeira (chamada de dinâmica de descontração) trazida por uma participante e que já havia sido acordado no último encontro. A brincadeira escolhida foi a de passar anel. Todos participaram de forma interessada (notas de observação participante, UBS 5).

Os usuários chegam aos grupos por vários caminhos. $\mathrm{O}$ convite direto, escrito ou verbal, feito pelo ACS é o mais comum. Outra forma de encaminhamento se dá através do acolhimento de algumas unidades. Os profissionais de saúde, a partir das consultas, também realizam encaminhamentos para os grupos. Os avisos anexados nas paredes funcionam como convites, além da divulgação feita pelos próprios usuários, bastante comum nos grupos mais concorridos: "Uma divulgação boca-a-boca, né?” (Usuária, Grupo focal, UBS 9).

Os grupos, em geral, demandam material de trabalho adicional que nem sempre é fornecido pela SMSA com tal finalidade. Um dos componentes a ser destacado são os "lanches" compartilhados nas atividades regulares e reforçados nas festas de encerramento, entre outras, que são bastante frequentes. Em geral, sua oferta é um elemento que faz aumentar a presença dos usuários. Algumas 
vezes são trazidos pelos usuários, mas na maioria dos casos fica por conta dos profissionais. Para públicos específicos, algo que pode parecer tão acessório, pode integrar o próprio planejamento da ação: "Não tem como trabalhar com adolescente durante duas horas sem ter lanche e ninguém banca esse lanche, a gente mesmo que tem que bancar" (Profissional, UBS 1).

Quanto à formação prévia e aos enfoques teórico-metodológicos utilizados, as respostas são bem variadas com apenas um denominador comum: a ampla maioria declara não ter recebido formação prévia para desenvolver práticas grupais: "A gente não recebe uma capacitação para trabalhar em grupo. A gente está aprendendo praticando mesmo" (Profissional, UBS 1).

As referências teóricas citadas são variadas, sem prevalência alguma de autores ou de métodos específicos. Alguns mencionados uma ou duas vezes são Paulo Freire, Lúcia Afonso, William Castilho Pereira, terapia comunitária de Adalberto Barreto, Pichón-Riviere, Rogers e seus grupos de encontro, artigos acessados no portal Scielo. Podemos supor que, nesse universo pesquisado, o êxito obtido nas práticas grupais depende menos do apuro teórico-metodológico, utilizado pelos profissionais e mais da disposição deles em aprender com as tentativas iniciais, atentando para o que funciona ou não, inclusive nas diferentes microáreas. Não é incomum que determinadas propostas funcionem bem em uma microárea, mas não consigam se estabelecer em outra.

A experiência de planejamento das práticas em reuniōes de equipe antes do encontro foi apontada como fator importante: "A gente senta primeiro com a equipe, discute, as pessoas vão dando ideias, ACS, todo mundo. Com as ideias a gente faz o pacote daquele semestre" (Profissional 2, UBS 3). Entretanto, quando os profissionais ficam tomados com o cotidiano da assistência sem tempo para planejamento das atividades, o trabalho fica comprometido. A equipe da UBS 6 faz o planejamento em conjunto, mas a condução fica a cargo do ACS responsável pela microárea, com a colaboração dos demais. $\mathrm{Na}$ sessão observada,

[...] a ACS sugere que cada participante defina saúde em uma palavra. Na sequência são divididos em dois subgrupos para discutirem o tema: "quais métodos você utiliza para manter sua saúde?”, para depois apresentarem ao outro subgrupo na forma de teatro e mímica. A enfermeira pediu para que falassem algo que faz mal à saúde e solicitou uma avaliação da atividade. Finalizaram através de uma sequência de exercícios físicos conduzida pelo médico e com um abraço coletivo (notas de observação participante, UBS 6). 
Existe uma tendência das práticas grupais acontecerem fora da unidade, em espaços da comunidade, seja pela precária infraestrutura da mesma (UBS 1), seja por causa do projeto de gestão que acredita na oportunidade de aproximação entre a equipe e a comunidade (UBS 6). Os usuários gostam dessa proximidade maior de sua residência. "O nosso grupo é o maior que tem. É bem pertinho da minha casa. E eu gosto muito” (Usuária, grupo focal, UBS 6). As alternativas são variadas: igrejas, escolas, associações comunitárias, organizações não-governamentais, parques e praças, residências oferecidas por usuários, entre outros.

A seguir, serão apresentados os diferentes "movimentos" que visam cartografar o desenvolvimento e a retração de processualidades encontradas na análise dos dados. Como se poderá perceber, a fronteira entre os movimentos escolhidos é tênue, e frequentemente eles se tocam e se atravessam.

\section{Primeiro movimento: por que fazer grupos?}

Ouvimos diferentes razões e justificativas para a realização dos grupos. Existem razões ligadas, de um lado, à organização dos serviços e, de outro, a um esforço de transformação das práticas de saúde tradicionalmente centradas na consulta médica. Alguns gerentes e profissionais (UBS 1,8) indicam a função dos grupos como estratégia para organização do excesso de demanda: "E aí eu trabalhando com eles essa questão que a demanda ela só ia diminuir a partir do momento que a gente criasse esses outros espaços, principalmente espaços de grupo pra que absorvesse essas pessoas" (Gerente, UBS 8).

Gerentes e profissionais apontam uma relação entre as práticas grupais e a diminuição da demanda na unidade. Um dos entrevistados avalia essa questão: "quando a gente tem grupo, diminui demais o acolhimento aqui. Então a gente resolve muita coisa lá nos grupos" (Profissional, UBS 7).

Contudo, nas palavras de uma profissional entrevistada, ocorre simultaneamente a produção de novas demandas, através do contato no grupo com pessoas que usualmente não frequentavam a unidade, mas inspiram cuidados: "Então pelo grupo a gente às vezes conhece um caso novo na área e tem que trazer pra consulta" (Profissional 2, UBS 6).

Nos depoimentos apontados acima, a preocupação quantitativa é evidente, mas existe concomitantemente o reconhecimento de uma dimensão qualitativa nessa organização: "A consulta individual é mais direcionada para aquela pessoa; 
o atendimento em grupo, já é para um grupo de pessoas, orientações mais diversas e mais gerais em relação à patologia, a gente fala sobre tudo" (Gerente, UBS 1).

Há uma compreensão de que a prática coletiva opera um descentramento em relação ao foco na patologia, próprio do atendimento individual. Tanto as práticas de grupo quanto as consultas podem ser entendidas como dispositivos no cuidado em saúde. Dispositivo é uma combinação de elementos heterogêneos, composto por elementos discursivos e não-discursivos e que coloca em ação determinado conjunto de experiências envolvendo campos de saber, de normatividade e de subjetivação (FOUCAULT, 1979).

O dispositivo "consulta individual" se apresenta como marcado pelo foco na doença, que o dispositivo "práticas de grupo" ajuda a desfocar, trazendo à tona outras dimensões de vida associadas à promoção da saúde. $\mathrm{O}$ reconhecimento de que as práticas grupais trazem a vida cotidiana dos usuários para a unidade com maior nitidez e intensidade é um elemento que atravessou vários depoimentos nos diversos contextos investigados, além de se apresentar nas observações participantes, como veremos na sequência.

Outros gerentes e profissionais acentuam mais diretamente o uso dos grupos como intenção de mudança do modelo exclusivamente biomédico na assistência:

Os grupos [...] têm sido tentativas de desmistificar um pouco o consultismo que existe, a busca pelo atendimento individual, sempre, exclusivo, e principalmente um modelo que até então é um modelo extremamente centrado no médico. [...] consulta e remédio (Gerente, UBS 3).

[...] Numa consulta você não consegue falar tudo que a gente fala no grupo, a consulta se restringe muito a resolver aquele problema que tá ali. A conversa do paciente, acho muito importante ouvir o que eles falam, você conhece melhor aquele paciente. (Profissional, UBS 7).

Evidentemente, as práticas coletivas não são sucedâneos das consultas individuais. Ambas têm alcances diferentes:

A atividade assistencial individual do consultório tem seu lugar, tem suas necessidades, mas é pra ser feita no consultório. E a ação coletiva com o foco em educação e promoção de saúde, essa sim poderia ser feita de uma forma coletiva (Profissional 1, UBS 6).

Seja por direção assumida no trabalho, seja como efeito desejável das práticas, os resultados diferenciais obtidos são reconhecidos, independentemente das razões de sua realização, "no grupo tem um momento melhor pra ela refletir, pensar, escutar, [...] muito mais que dentro da consulta” (Gerente, UBS 5). 
Contudo, essa avaliação fala de um movimento de mudanças que não éhegemônico. A hegemonia, na atenção básica, pertence ao dispositivo "consulta-medicação", o que é atestado, não sem lamentos, por gerentes, profissionais e usuários:

[Os usuários] ficam assim: "não, eu quero é consultar, eu quero é medicamento", entendeu? Até eles entenderem que existem outros métodos para melhorar a saúde dele, isso é difícil. (Gerente, UBS 5)

A saúde hoje, eu acho que melhorou muito, mas aí as pessoas veem o foco só de tomar remédio, tomar remédio, tomar remédio e muitas vezes não é isso. (Usuária, grupo focal, UBS 5)

Nessa microárea [...] é uma população mais resistente ao tratamento preventivo, ela gosta é do curativo, ela gosta é de consulta, remédio, de exame. (Profissional, UBS 7)

Encontramos a prevalência da demanda dos usuários face à oferta histórica de assistência centrada na consulta-medicação. Até em unidades onde as equipes têm construído uma proposta mais ampliada de práticas de cuidado em saúde, permanece a pressão por parte de muitos usuários da oferta clássica dos serviços. Mesmo assim, uma discussão mais aprofundada das condições de produção do excesso de demanda nas unidades não se fez presente durante a realização das entrevistas e observações.

\section{Segundo movimento: mudanças no enfoque das práticas grupais}

A já mencionada diretriz da SMSA, incentivando a organização de grupos a partir de novos eixos estruturantes, discutida nas UBSs em 2006, encontrouse com uma tendência de transformação dos antigos grupos organizados por patologias. Em várias unidades, é visível o esgotamento de um modelo mais clássico, centrado em doenças, no modelo de palestra seguida de perguntas.

Esse grupo, a gente adotou no lugar do antigo grupo de diabéticos hipertensos que a gente tinha na unidade. Era um grupo cansativo, repetitivo, batendo sempre naquela mesma tecla. Não era um modelo ideal pra grupo operativo e acabou que todo mundo caiu em si e viu que tava precisando mudar (Profissional, UBS 4).

Esse tipo de avaliação apareceu na maioria das unidades pesquisadas. Alguns grupos-doença vão se dissipando por esgotamento, tornando-se cansativos tanto para usuários quanto para profissionais. Por vezes, a iniciativa é dos profissionais: "quando vieram a [enfermeira e o médico] e propuseram fazer diferente e eu 
topei” (Gerente, UBS 6). Outras, como vimos anteriormente, proveem de uma proposta gerencial: “o [grupo] da hipertensão, a gente realizava muito o grupo, mas assim... Com a pessoa focada na doença dela, e nós queremos tirar muito isso, então nós estamos fazendo um movimento diferente” (Gerente, UBS 2).

Em algumas unidades, testemunhamos o desenrolar de um processo paulatino de deslocamento das práticas. Alguns grupos, inicialmente organizados a partir de doenças no modelo palestra-perguntas, transformaram-se em grupos de convivências com desenho mais participativo e temáticas mais variadas. Em alguns casos, eles sofreram um segundo deslocamento, passando a ser assumidos por voluntários da comunidade. Esse movimento ocorreu com frequência na UBS2.

Não tinha mais o posto pra assumir a atividade física porque faltavam profissionais. E aí o grupo já tava entrosado, já tinha uns seis, cinco anos de caminhada. E pra não deixar o grupo acabar nós nos propusemos a continuar. Aí eu me ofereci na época como voluntária, uma outra também se ofereceu, e o grupo continuou. A presença dos profissionais é muito importante, mas o grupo caminha independente (Usuária, grupo focal, UBS 2).

Esse movimento é legitimado pelos profissionais. Um ponto chama a atenção: esses grupos desenvolvem atividades físicas ou artesanais, que independem da referência teórico-técnica em saúde. Pode-se, assim, prescindir do profissional.

E é um desafio porque a minha vontade era dar continuidade a esses grupos como um grupo auto-organizado [...] Nesses grupos de convivência são as mulheres que coordenam as oficinas, então são elas que dão aulas de atividades que elas queiram dar aulas e convidam outras mulheres. As ACSs também ajudam. É uma forma que a própria comunidade tem de se organizar e estar ali no coletivo podendo trocar experiências, um ensina ao outro bordado, crochê, pintura... (Profissional 2, UBS 6).

Contudo, essa interpretação não é unânime. Na observação participante realizada em um grupo-oficina de artesanato, cuja composição inicial era de mulheres em uso continuado de antidepressivos, a auxiliar de enfermagem que dele participa entende que "o grupo perdeu o foco, está parecendo mais uma aula de artesanato", enquanto no passado fazia-se, segundo ela "terapia de grupo" (observação participante, UBS 2). Parece que um formato alternativo, sem uma aparente relação direta com um saber técnico que caracteriza uma ação de saúde, nem sempre é visto como prática de saúde.

Outro aspecto da dificuldade desses grupos nessa unidade é que, por terem grande adesão por parte dos usuários, os voluntários ficam sobrecarregados em suas funções, pois há uma recusa geral em interrupções, ou mesmo férias. 
Em uma avaliação feita em 2007, pela então gerente de assistência da SMSA, foi apontado como objetivo ainda a ser alcançado pelas práticas de promoção da saúde, "a necessidade de aumento dos níveis de autonomia e protagonismo" (informação verbal). ${ }^{1}$ A discussão sobre os alcances e limites dos grupos autogeridos no contexto da saúde pública merece maior aprofundamento em outra ocasião.

\section{Terceiro movimento: informação e participação}

A atenção à saúde se constitui em um modelo de cuidado dependente de saberes técnicos especializados. Nesse sentido, a informação especializada é um componente inerente à produção do cuidado em saúde. Contudo, a informação apresentada de um modo prescritivo hierarquizado, e muitas vezes através de um jargão técnico hermético, obtém poucos efeitos significativos no universo da população atendida pelo SUS. Por essa razão, é crescente o debate e as iniciativas em torno de metodologias participativas no trabalho em saúde (ROZEMBERG, 2006). A própria Política Nacional de Promoção da Saúde (PNPS) possui forte ênfase na dimensão participativa das práticas de saúde.

Trabalhamos com a idéia de que informação e participação no trabalho em saúde não são categorias excludentes, mas concomitantes. Todo trabalho em saúde possui um compromisso inexorável com o conhecimento especializado, ainda que em sua ação possa se apresentar mais centrado no conhecimento técnico ou de um modo mais dialógico, que abarque uma troca e construção coletiva de saberes e fazeres.

Pela tradição mais arraigada na saúde de utilização do recurso da palestra como procedimento principal de comunicação, a implementação de índices de participação não se processa de modo automático. As observações participantes nos grupos indicaram que, por vezes, o cenário se mostrou aquém da intenção indicada pelas equipes que apostam no foco participativo das práticas de promoção da saúde. Existe um avanço maior na introdução de novos temas do que na introdução de novas metodologias de condução dos grupos.

Como exemplo da defasagem entre a intenção dos profissionais e a prática de fato realizada, apresentamos a condução de um grupo denominado de "promoção da saúde”. 
O processo ocorre com uma palestra feita pela médica sobre o tema escolhido (obesi-

dade), seguido de perguntas por parte das usuárias e distribuição de um texto "Raízes Biológicas da Obesidade”. Ao final houve uma votação sobre qual tema gostariam de abordar no próximo encontro (observação participante, UBS 4).

Existe um interesse em promover participação, que nem sempre se efetiva plenamente no modo de condução do grupo. Uma profissional dessa mesma unidade diagnosticou a dificuldade: "Eu acho que você tem ter um traquejo muito grande pra coordenar um grupo, senão você fica ali como a figura central, você não escuta o outro, você não faz essa troca de sabedoria popular com o científico" (Profissional, UBS 4). Esse aspecto aponta diretamente para o campo da formação dos profissionais de saúde, ainda muito marcada pela maior valorização dos aspectos técnicos, particularmente do âmbito biomédico, em detrimento dos aspectos psicossociais.

No depoimento de alguns usuários, podemos recolher um pouco dessa interface entre informação e participação nos grupos: "É o que passa naquele grupo, é aquela palestra que tá ali. Eles passam uma ginasticazinha pra gente, a gente canta, alguém toca violão, toca aquelas músicas antigas, ali ajuda muita gente" (Usuária, grupo focal, UBS 6). Na fala, reconhecem-se os benefícios das informações expositivas associadas a atividades participativas.

Percebe-se que há uma prevalência dos aspectos informativos nos grupos tradicionais, organizados por patologia ou temática fechada, e maior gradiente participativo em grupos organizados por novos eixos estruturantes. Ainda assim, os usuários indicam que, mesmo nos grupos tradicionais, as explicações se apresentam de modo mais acessível e convincente: "elas têm muita paciência pra explicar pra gente direitinho, sabe? [...] Têm o dom pra explicar direitinho, muita coisa que a gente não sabia hoje a gente tá aprendendo com elas” (Usuária, Grupo focal, UBS 5).

O clima menos formal e mais afetivo, promovido pelo dispositivo "práticas de grupo", é apontado como fator facilitador de mudanças nos modos de viver dos usuários. Os grupos se apresentam como espaços de informação, mas também de intervenções carregadas de afeto. Uma usuária assinala que o grupo serve para "a médica puxar a orelha de quem engordou mais..." (Usuária, Grupo focal, UBS 5). Outra usuária aponta: "Eu tinha muita preguiça de fazer caminhada, mas depois que o doutor D. recomendou, eu resolvi fazer. E aí estou me sentindo bem melhor" (Usuária, observação participante, UBS 6). 


\section{Quarto movimento: efeitos das práticas grupais}

No movimento 1, já apontamos um primeiro importante efeito das práticas grupais, o descentramento em relação ao foco na patologia, próprio do atendimento individual, na direção de uma abordagem integral das condições e dos modos de vida dos usuários. Neste tópico, analisaremos outros quatro efeitos relevantes, assinalados por gerentes, profissionais e usuários. Devido ao espaço limitado do formato artigo, privilegiaremos a fala dos usuários na análise deste movimento.

O primeiro efeito dos grupos é de suporte para condições de vida difíceis, portanto, um dos objetivos da promoção da saúde.

A pessoa às vezes sai de casa com dor de cabeça, passando mal, preocupação com algum problema e chega lá, acaba esquecendo. Por quê? Porque ela vê outras pessoas contando alguma história, porque ele faz algum exercício físico, um alongamento, depois às vezes um conta história, a gente dá risada... Então é muito calmante, é muito relaxante. (Usuária, grupo focal, UBS 6).

Os profissionais também reconhecem que, diante da violência, da fome, das precariedades da vida, dos conflitos familiares, a única porta aberta é a UBS, onde tudo é recebido. As práticas de grupo se mostram, nessa perspectiva, uma estratégia de suporte significativa.

O segundo efeito, associado ao primeiro, é o de criação de espaços de sociabilidade. São vários usuários, com vínculos sociais e familiares estreitos, que encontram nos grupos formas de estabelecer laços de amizade e solidariedade.

É um grupo grande, com uma presença boa. Quando um não vai os outros se preocupam, perguntam por que aquela pessoa tá sumida, se tá doente (Usuária, grupo focal, UBS 2).

Então, é a união e aí a gente acaba fazendo uma amizade sabe? Novos amigos, sabe? (Usuário, Grupo focal, UBS 8).

eu sou muito sozinha, que eu moro sozinha, meu filho trabalha, então foi muito bom ter vocês como amigas, a gente conversa com um, conversa com outro, faz muito bem pra gente [...] eu sentia muito solitária, cheia de problema sabe, tô muito feliz. (Usuária, UBS 9)

O terceiro efeito é o de troca de conhecimentos entre usuários e entre estes e os profissionais.

Uma senhora relatou que usa o óleo restante da fritura para fazer sabão, uma das acadêmicas disse que isso é consciência ecológica. Uma das enfermeiras sugeriu que esta senhora trouxesse no próximo encontro a receita de como fazer o sabão (Observação participante, UBS 5). 
Eu acho que é interessante, porque além da gente aprender muita coisa, eles também

aprenderam sobre a [comunidade], a gente apresentou o bairro todo, e a gente também aprendeu com eles. (Usuária, grupo focal, UBS1).

Na realidade a gente aprende com eles mesmos, com o dia-a-dia deles. (Gerente, UBS 4).

Um último efeito a ser destacado é o do fortalecimento e qualificação dos vínculos entre os usuários e as equipes. Escutamos em relação a isso depoimentos bastante contundentes e selecionamos alguns dos mais representativos:

E através do grupo a gente fica tendo mais liberdade pra conversar com o pessoal do posto, né? Com os agentes de saúde, com os médicos, a gente tem mais facilidade, mais intimidade com eles (Usuária, grupo focal, UBS 2).

Tem pessoa que só conversou com o doutor D. na hora da consulta. Ela não sabe da vida do doutor D. lá fora, eu sei da vida do doutor D. lá fora, porque ele participa com a gente nos grupos e apesar dele não contar a história de vida dele pra gente, mas nós temos outras coisas como as comemorações, que às vezes a gente faz, ele vem, ele participa... Então, a gente já sabe o tipo de pessoa que ele é fora da consulta. E eu acho isso muito importante. (Usuária, grupo focal, UBS 6).

Os profissionais também enfatizam a importância do fortalecimento e da qualificação dos vínculos com os usuários.

Então, a gente vê que eles ficam mais ligados à gente, porque o contato é muito próximo quando a gente tem grupo. Então às vezes encontra com a gente na rua e para e conversa, então fica uma intimidade e eu acho que isso cria mais confiança (Profissional, UBS 7).

Eu consigo ver que a questão do vínculo, ela é muito fortalecida e, assim sendo, o respeito, a cooperação, também desde que você precise que o usuário entenda o processo de trabalho, quando ele tem um vínculo com você, ele entende isso de uma forma muito melhor. Carinho, amizade, isso tudo a gente consegue perceber e é bilateral, porque você vai ficando mais próximo daquele usuário, no passeio, de repente, ele senta do seu lado e começa a te contar um pouco mais da vida dele [...] acaba com essa coisa muito médico-paciente, enfermeiro-paciente, somos seres humanos, eu cuido de você, você cuida de mim e a gente se ajuda (Profissional, UBS 9).

Vislumbramos, portanto, uma produção qualificada de vínculos, desencadeando processos de subjetivação diferenciados, tanto dos usuários quanto das equipes. Aqui, o ideário da humanização encontra uma clara realização, associada ao enfraquecimento das identidades rígidas de pacientes e de profissionais, promovida por esse dispositivo. Embora as questôes relativas à humanização não sejam foco do estudo, encontramos nas práticas de grupo uma importante tecnologia relacional, do "como fazer" visado pela Política Nacional 
de Humanização, lembrando que "é a partir da transformação dos modos de os sujeitos entrarem em relação, formando coletivos, que as práticas de saúde podem efetivamente ser alteradas" (BENEVIDES; PASSOS, 2005, p. 392).

\section{Quinto movimento: avaliação das práticas grupais}

Este último movimento também já apareceu nos anteriores. Não existe uma política de avaliação das práticas de promoção da saúde estabelecida pela SMSA de Belo Horizonte. Entendemos que, para a construção disso, é necessário não se restringir a procedimentos normativos de avaliação, mas entender que a avaliação tem por função "favorecer as potencialidades das práticas de saúde para gerar processos criativos e solidários de melhoria da qualidade de vida" (AYRES, 2004, p. 590). Entendemos também existir um permanente processo de avaliação no desenvolvimento de práticas em geral, em alguns casos de modo mais formalizado, em outros de modo mais intuitivo. Essa permanente atitude avaliativa produziu, em nossa percepção, algumas das práticas mais interessantes que conhecemos e que não nasceram prontas. Muitas surgiram de um percurso anterior de tentativas e readequações. Algumas tiveram seu apogeu em momentos anteriores e necessitam de revisões posteriores. A atenção avaliativa permanente é um elemento essencial do "êxito" das experiências.

Ayres (2004) faz um contraste entre avaliação normativa e avaliação formativa. $\mathrm{Na}$ ausência da primeira, pois não existe na SMSA uma ação avaliativa das práticas grupais, voltamo-nos para a segunda modalidade.

Um exemplo sobre o valor da avaliação formativa realizada por uma ESF pode ser vislumbrado na UBS 6. Quando novos profissionais chegaram ao serviço, fizeram a proposta de abolir os grupos centrados em doenças, transformandoos em grupo de promoção da saúde. O primeiro resultado foi um esvaziamento dos grupos existentes. Somente após um período de implantação das novas práticas é que os grupos foram refeitos e a participação se intensificou. Essa mesma equipe desenvolveu um registro da frequência tanto nos grupos quanto na unidade. Num primeiro momento, houve uma diminuição da frequência na unidade, tal como relatado em outras UBSs. Posteriormente, houve novo aumento na frequência, o que deixou a equipe surpresa. A percepção que tiveram foi de que o aumento da presença na unidade tinha outra função, diferente de chegar ao acolhimento buscando consulta. Muitos usuários buscavam 
os profissionais para dar notícias da vida pessoal, para buscar indicações ou informações sobre temas variados. Por isso, uma avaliação não normativa, especialmente não exclusivamente quantitativa, revela-se como elemento vital para o aprimoramento e inovação das práticas em saúde.

O primeiro elemento saliente foi que, apesar da escassez de recursos institucionais para avaliação, ela é objeto de interesse por parte das equipes. $\mathrm{O}$ que existe formalizado na SMSA é uma "folha de produção" contendo o número de usuários e profissionais participantes, a modalidade e um espaço para fazer um resumo dos temas abordados. Algumas equipes partem disso para um primeiro esboço de avaliação. A profissional da UBS 1 aponta que o número de crianças internadas da microárea "caiu drasticamente depois da puericultura".

$\mathrm{Na}$ maior parte das UBSs investigadas, existe uma avaliação positiva das práticas de grupo, mesmo que essa avaliação seja feita de modo informal.

Tem uma avaliação mais informal. [...] existe uma satisfação muito grande do usuário [...] os outros usuários que não tinham grupo ficaram sabendo e falavam assim "uai, mas o meu, minha equipe não vai ter grupo operativo?" (Gerente, UBS 5).

Algumas unidades fazem avaliações formais com registros escritos, utilizando indicadores próprios e/ou acolhendo avaliações feitas por equipes de estagiários, como ocorreu na UBS 2.

Os indicadores qualitativos mais mencionados foram: satisfação do usuário, qualidade de vida, estabilização das doenças crônicas, diminuição no uso de medicamentos especialmente ansiolíticos e antidepressivos, fortalecimento dos vínculos. Os indicadores quantitativos mencionados foram: a diminuição de pacientes no acolhimento, o aumento da frequência nos grupos, diminuição no número de internações ou quadros agudos.

A construção de uma futura proposta formal de avaliação deveria desenvolver seus indicadores em diálogo com as experiências das equipes e dos usuários, num processo coletivo e participativo de trabalho (MINAYO; ASSIS; SOUZA; 2005).

Em relação às limitações das práticas grupais, alguns fatores se destacam. Dificuldades de infraestrutura, que envolve o próprio espaço físico da unidade, a falta de verba específica para lanches e organização de festas, a dificuldade com o transporte para as equipes desenvolverem os grupos nas microáreas, entre outras. A fala de uma profissional sintetiza essas questões: "É cobrado muito da gente com relação ao trabalho em grupo, mas o apoio institucional é muito pequeno" (Profissional, UBS 4). 
Algumas demandas específicas se apresentaram, como por exemplo, a remuneração para monitores de grupos, em uma das modalidades mais demandadas, a dança de salão: "Eu senti muito porque a dança ele é um exercício completo, mas nós não temos verba pra pagar um monitor" (Gerente, UBS 2). Houve queixas sobre a baixa adesão e participação dos usuários em relação a alguns grupos, em geral grupos de conversa tradicionais (diabéticos, hipertensos, gestantes). Os grupos de atividades e os de conversa baseados em novos eixos, em geral, apresentam uma participação mais significativa.

Outros elementos bastante mencionados foram a falta de formação específica para o trabalho com grupos e a pressão da assistência, dificultando tanto o desenvolvimento das práticas coletivas quanto o necessário planejamento e registro delas. Nesse caso, unidades com um número maior de equipes se veem com certa vantagem.

A gente tem que fazer todas as outras práticas, tem que atender, tem que ter as consultas programadas, tem o agudo toda hora, mas apesar disso a gente tem uma vantagem aqui de seis equipes, o que facilita um pouquinho pra cobrir a unidade e ainda conseguir ter as práticas (Gerente, UBS 9).

\section{Considerações finais}

$\mathrm{O}$ volume de dados e análises produzidas no desenrolar da pesquisa permite a abordagem dos movimentos aqui apresentados, mas não se esgota num único artigo. Dois temas que merecem ser mencionados são a avaliação das práticas de promoção da saúde e o manejo das práticas grupais como tecnologia de cuidado na saúde. Esses temas serão oportunamente trabalhados em profundidade, mas antecipamos sua relevância no conjunto da pesquisa.

Nossa amostra investigada foi composta de UBSs com práticas grupais mais consolidadas, portanto, não reflete a média do que acontece hoje na rede. Nossa busca visava a encontrar práticas emergentes, não necessariamente hegemônicas. Não objetivamos, assim, a generalização dos elementos aqui apresentados, mas seu reconhecimento e, se possível, sua intensificação, estimulando a disseminação e criação de novas práticas. Entretanto, a saliência dada às ações voltadas para a promoção em relação às focadas na prevenção, não ignora, como vimos, o valor e o alcance das práticas de grupo tradicionais.

De várias maneiras testemunhamos a força do dispositivo "práticas de grupo na atenção à saúde", realizando mais do que se previa inicialmente, como na 
transformação subjetiva do vínculo entre os atores envolvidos (profissionais e usuários), na alteração da forma de acessar a UBS por parte dos usuários e na criação de novas redes de apoio, sociabilidade e afetividade entre a comunidade e com a unidade. Entendemos que esse dispositivo carrega uma potência de transformação das ações de cuidado e de "produção de subjetividades ativas e solidárias” (BRASIL, 2006, p. 13), um dos objetivos da PNPS.

Se a prática hegemônica de grupos na saúde ainda possui um modelo estrito de formato palestra-perguntas, historicamente bem assentado e mais próximo do dispositivo "consulta", as novas práticas de promoção da saúde têm uma face mais diversificada, constituindo-se em experiências quase singulares. Por conseguinte, sua reprodutibilidade não se revela tendo a mesma eficácia. Na UBS 4 , por exemplo, os grupos realizados em residências de moradores funciona bem em uma microárea, e não tão bem em outra.

Devido a seu caráter de arranjo singular, produzido mediante uma trajetória de tentativas, avaliações e mudanças, agregando elementos próprios da população atendida e do perfil dos profissionais, tomá-las como padrão a ser replicado em outros contextos (tentação comum em gestores) pode trazer dois tipos de efeitos indesejados. O primeiro é a dificuldade de reviver o engajamento de profissionais e usuários, que ocorre quando eles são agentes do processo de construção coletiva das práticas. O segundo é o de enfraquecer e não legitimar a criatividade emergente nesses processos de invenção de novas formas de cuidado, que estão presentes em muitos dos municípios de nosso País. Divulgá-las e criar espaços para a troca de experiências entre as UBSs pode ser uma estratégia para sua intensificação e multiplicação.

\section{Agradecimentos}

Agradecemos o apoio da Fundação de Amparo à Pesquisa do Estado de Minas Gerais (FAPEMIG).

\section{Referências}

AYRES, J. R. Norma e formação: horizontes filosóficos para as práticas de avaliação no contexto da promoção da saúde. Ciência \& Saúde Coletiva, v. 9, n. 3, p. 583-592, 2004.

BECHELLI, L.P; SANTOS, M.A. Psicoterapia de grupo: como surgiu e evoluiu. Revista Latino-Americana de Enfermagem, v. 12, n. 2, p. 242-249, 2004. 
BENEVIDES, R.; PASSOS, E. Humanização na saúde: um novo modismo? Interface Comunic, Saúde, Educ, v. 9, n. 17, p. 389-406, 2005

BRASIL. Ministério da Saúde. Secretaria de Políticas de Saúde. Projeto Promoção da Saúde: as cartas de promoção da saúde. Brasília: Ministério da Saúde, 2001.

BRASIL. Ministério da Saúde. Atenção Básica e a Saúde da Família. Disponível em <http:// dtr2004.saude.gov.br/dab/atencaobasica.php>. Acesso em: 20 fev. 2009.

BRASIL. Ministério da Saúde. Política Nacional de Promoção da Saúde. Brasília: Ministério da Saúde, 2006.

BUSS, P. Uma introdução ao conceito de promoção da saúde. In CZESRESNIA, D.; FREITAS, C.M. (Org.). Promoção da Saúde: conceitos, reflexões, tendências. Rio de Janeiro: Fiocruz, 2003. p. 15-38.

CARVALHO, S.R. As contradições da promoção à saúde em relação à produção de sujeitos e a mudança social. Ciência e saúde coletiva, Rio de Janeiro, v. 9, n. 3, p. 669-678, 2004.

CARVALHO, S.R.; GASTALDO, D. Promoção à saúde e empoderamento: uma reflexão a partir das perspectivas crítico-social e pós-estruturalista. Ciência e saúde coletiva, Rio de Janeiro, v. 13 sup. 2, p. 2029-2040, 2008.

CASTIEL, L.D. Promoção de saúde e a sensibilidade epistemológica da categoria “comunidade". Revista de Saúde Pública, São Paulo, v. 5, n. 38, p. 615-622, 2004.

CZERESNIA, D. O conceito de saúde e a diferença entre prevenção e promoção. In CZESRESNiA, D.; FREITAS, C.M. (Org.). Promoção da Saúde: conceitos, reflexōes, tendências. Rio de Janeiro: Fiocruz, 2003. p. 39-53.

ESCOREL, S. et al. O Programa de Saúde da Família e a construção de um novo modelo para a atenção básica no Brasil. Rev Panam Salud Publica, v. 21, n. 2, p. 164-176, 2007.

GIOVANELLA, L. Atenção Primária à Saúde. In: GIOVANELLA, L. et al. (Org.). Políticas e sistema de saúde no Brasil. Rio de Janeiro: Fiocruz, 2008. p. 575-625.

GRISOTTI, M; PATRÍCIO, Z. A saúde coletiva entre discursos e práticas: a participação de usuários, trabalhadores e conselheiros de saúde. Florianópolis: EdUFSC, 2006.

FERNANDEZ, A.M. O campo grupal: notas para uma genealogia. São Paulo: Martins Fontes, 2006.

FERREIRA NETO, J.L.; KIND, L. Promoção da saúde: uma discussão teóricometodológica a partir de Foucault. In: FERREIRA NETO, J.L.; LIMA, E.A.; ARAGON, L.E. (Org.). Subjetividade contemporânea: desafios teóricos e metodológicos. Curitiba: CRV, 2010, p. 43-60.

FOUCAULT, M. Microfísica do poder. Rio de Janeiro: Graal, 1979.

FOUCAULT, M. Mesa-redonda em 20 de maio de 1978. In:___Estratégia poder-saber. Rio de Janeiro: Forense Universitária, p.335-351. 
MINAYO, C.; ASSIS, S.; SOUZA, E, (Org.) Avaliação por triangulação de métodos: abordagem de programas sociais. Rio de Janeiro: Fiocruz, 2005.

RODRIGUES, H.B.C. Sobre as histórias das práticas grupais: exploraçōes quanto a um intrincado problema. In: MANCEBO, D.; JACÓ-VILELA, A.M. (Org.) Psicologia Social: abordagens sócio-históricas e desafios contemporâneos. 2a ed. Rio de Janeiro: EdUERJ, 2004. p. 113-167.

ROZEMBERG, B. Comunicação e participação em saúde. In: CAMPOS. G.W.S. et al. Tratado de Saúde Coletiva. São Paulo: Hucitec, 2007. p. 741-766.

TURATO, E D. Tratado da metodologia da pesquisa clínico-qualitativa. Petrópolis: Vozes, 2003.

TURCI, M.A. Avanços e desafios na organização da Atenção Básica à Saúde em Belo Horizonte. Belo Horizonte: Secretaria Municipal de Saúde, 2008.

\section{Nota}

${ }^{1}$ Sônia Gesteira, então Gerente de Assistência da SMSA, em palestra no I Fórum Regional de Promoção da Saúde nas Práticas Cotidianas dos Serviços, ocorrido na Universidade Federal de Minas Gerais, em 20/05/2007. 


\section{Group practices as health promotion device} This paper presents and discusses data from a research about group practices developed by Family Health Teams of the nine Sanitary Districts of Belo Horizonte city. We conducted interviews with managers and health professionals from Basic Health Units, focus groups with customers and participant observation of regular groups of health units. In data analysis we aimed to highlight the process dimension and the historical construction of the investigated practices through the discussion of five aspects: (1) reasons to promote group practices; (2) changes on the structure of group practices; (3) informative and participative dimensions of the groups; (4) effects and (5) assessment of group practices. The analyses show that group practices have multiple aspects related to services organization and healthcare, the function and objectives placed by different teams, and its configuration. There is an incipient shift of approach concerning practices centered in diseases for the creation of groups by new structural axis, according to the municipal guidelines for primary health. Data show the impact of group practices in reducing the request for individual appointments and in enhancing the bond between customers, health professionals and services. The results indicate the tension between the "individual appointment" device and the "group practices" device. The former is marked by the focus in disease, while the latter produces its blurring, highlighting other dimensions of life associated with health promotion.

> Key words: Health Promotion; group practices; family healthcare; device. 